\title{
Closure of an intestinal perforation with an auto- logous fat plug in a man with Crohn's disease
}
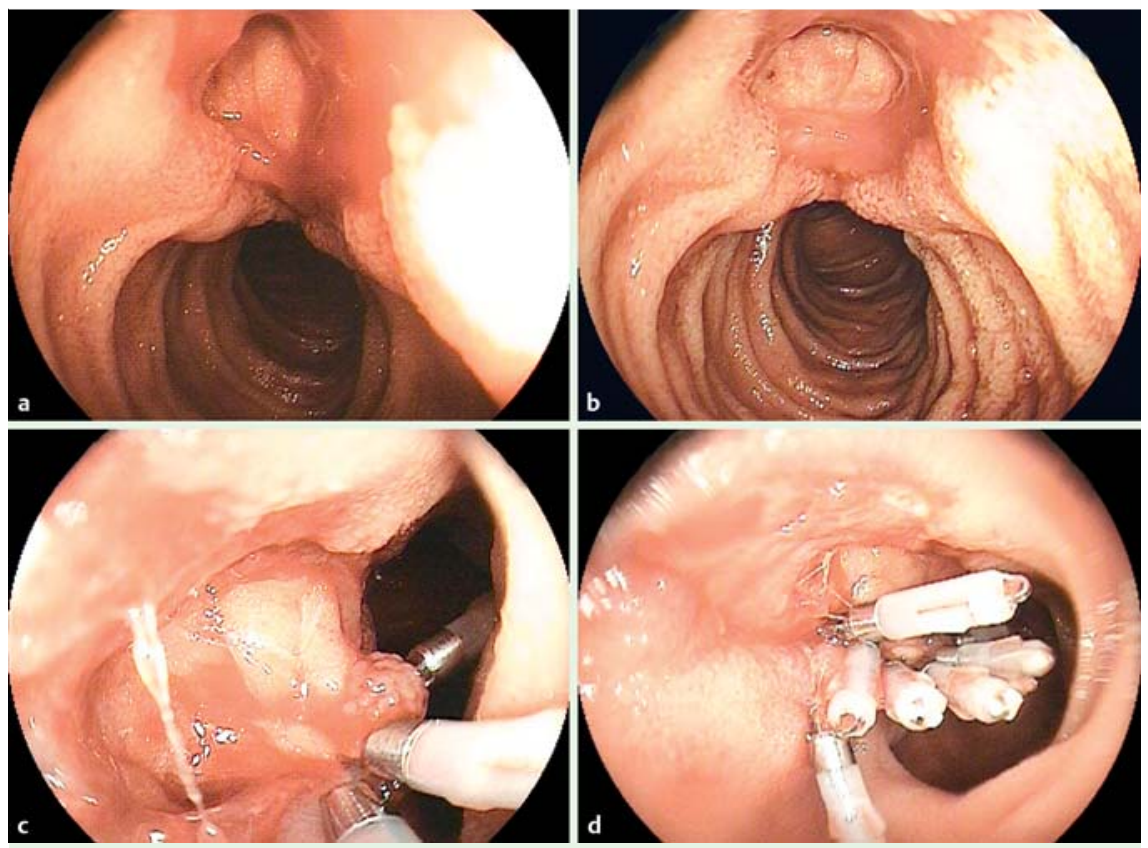

Fig. 1 View during double-balloon enteroscopy (DBE) showing: $\mathbf{a}$ an intestinal perforation in the lower part of the ileum; b fatty tissue pulled up from the peritoneal cavity to plug the perforation; $\mathbf{c}, \mathbf{d}$ clips that were placed on the fatty plug to prevent its dislocation.
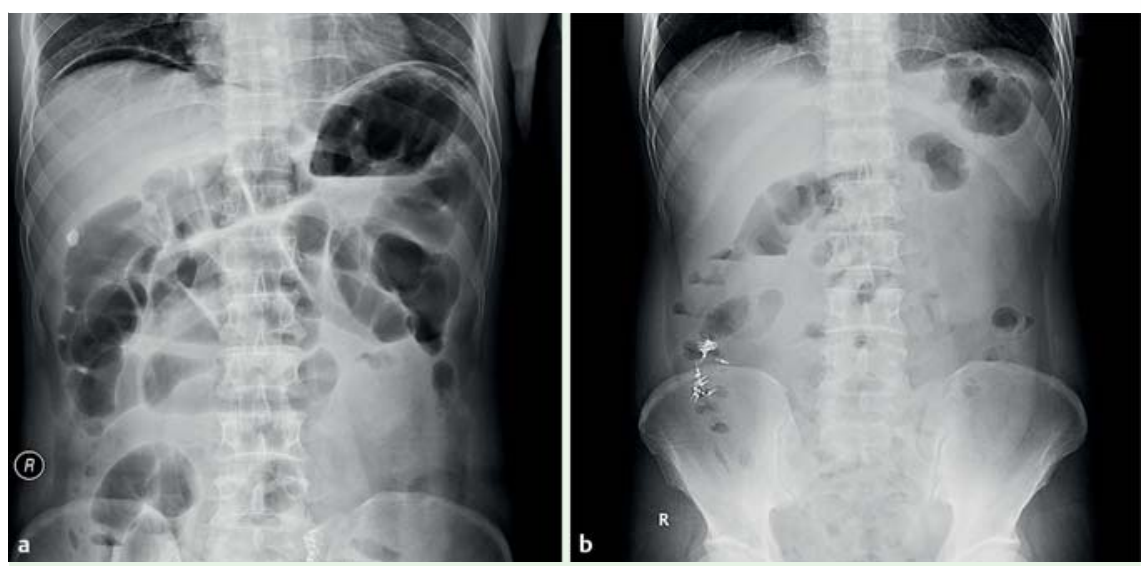

Fig. 2 Abdominal plain films showing: a subphrenic gas immediately after the procedure, consistent with an intestinal perforation; $\mathbf{b}$ absence of the subphrenic gas 1 week later, indicating successful closure of the perforation.

A 44-year-old man presented to our hospital with a 4-year history of recurrent abdominal pain and diarrhea. It had been suspected at his local hospital that he had Crohn's disease, so he came to our hospital for a further assessment. Retrograde double-balloon enteroscopy (DBE) was performed. A perforation overlying a deep ulcer was seen at the lower part of the ileum during withdrawal of the enteroscope ( $\bullet$ Fig. 1 a).

We collected some fatty tissue from the peritoneal cavity, most probably from the nearby mesenteric fat, and pulled it back through the perforation to act as a plug ( $\bullet$ Fig.1b). Several clips were placed on the fatty plug to prevent its dislocation ( $\bullet$ Fig. 1 c, $\bullet$ Fig. 1d). Immediately after the procedure, an abdominal plain film showed subphrenic gas, consistent with an intestinal perforation ( $\mathbf{F i g . 2 a}$ ). He had no signs of acute peritonitis, but had a low grade fever for 2 days so received intravenous antibiotics. A repeat abdominal plain film 1 week later revealed absence of the subphrenic gas ( $\bullet$ Fig. 2 b), indicating that the perforation had been successfully closed.

He was eventually diagnosed with Crohn's disease and was discharged home with oral methylprednisolone and azathioprine. His symptoms resolved and capsule endoscopy 6 months later revealed improvement of the lesions and absence of the perforation.

Surgical management is the first-line treatment of intestinal perforation $[1,2]$; however, it is an invasive method with a high risk of complications, even mortality, and recurrence is a common concern for patients with Crohn's disease. Closure of a perforation with an autologous fat plug has been performed in the stomach and colon, and has shown promising results [3-5]. In the present patient, intestinal perforation was encountered during DBE and was successfully closed with an autologous fat plug, which prevented the patient from needing surgery with its associated morbidity. To the best of our knowledge, this is the first report of iatrogenic intestinal perforation in a patient with Crohn's disease that was managed by autologous fat plug closure.

\section{Endoscopy_UCTN_Code_CPL_1AJ_2AG}

Competing interests: None

\section{Yuyong Tan, Dalian Ou, Xuehong Wang, Jie Zhang, Deliang Liu, Jirong Huo}

Department of Gastroenterology,

The Second Xiangya Hospital of Central South University, Changsha, Hunan, China

\section{References}

1 Chavalitdhamrong D, Adler DG, Draganov PV. Complications of enteroscopy: how to avoid them and manage them when they arise. Gastrointest Endosc Clin N Am 2015; 25: 83-95

2 Paspatis GA, Dumonceau JM, Barthet $M$ et al. Diagnosis and management of iatrogenic endoscopic perforations: European Society of Gastrointestinal Endoscopy (ESGE) Position Statement. Endoscopy 2014; 46: $693-$ 711

3 Hashiba K, Carvalho AM, Diniz G Jr et al. Experimental endoscopic repair of gastric per- 
forations with an omental patch and clips. Gastrointest Endosc 2001; 54: 500-504 4 Minami S, Gotoda T, Ono $\mathrm{H}$ et al. Complete endoscopic closure of gastric perforation induced by endoscopic resection of early gastric cancer using endoclips can prevent surgery (with video). Gastrointest Endosc 2006; 63: 596-601

5 Pham KD. Closure of a colon perforation with an autologous fat plug. Endoscopy 2015; 47 (Suppl. 01): E111

\section{Bibliography}

Dol http://dx.doi.org/

10.1055/s-0042-111324

Endoscopy 2016; 48: E257-E258

(C) Georg Thieme Verlag KG

Stuttgart · New York

ISSN 0013-726X

\section{Corresponding author}

\section{Deliang Liu, MD}

Department of Gastroenterology

The Second Xiangya Hospital of Central South University

NO. 139 Middle Renmin Road

Changsha

Hunan, 410011

China

Fax: 86-0731-85533525

liudeliang@medmail.com.cn 